\title{
OPTIMIZATION OF GROUND CONTROL POINT (GCP) AND INDEPENDENT CONTROL POINT (ICP) ON ORTHORECTIFICATION OF HIGH RESOLUTION SATELLITE IMAGERY
}

\author{
Teguh Hariyanto ${ }^{1, *}$, Akbar Kurniawan ${ }^{2}$, Cherie Bhekti Pribadi ${ }^{1}$, and Rizal Al Amin ${ }^{1}$ \\ ${ }^{1}$ Geomatics Engineering Department, Faculty of Civil, Environment, and Geo Engineering, Institut Teknologi Sepuluh \\ Nopember
}

\begin{abstract}
In the rapidly evolving technology era, various survey methods have been widely used one of them by remote sensing using satellite. It is known that the satellite image recording process is covered by rides (satellites) moving over the Earth's surface at hundreds of kilometers, causing satellite imagery to have geometric distortion. To reduce the effect of geometric distortion of objects on the image, geometric correction by orthorectification is done. Pleiades is a satellite of high resolution satellite image producer made by Airbus Defense \& Space company. The resulting satellite imagery has a 0.5 meter spatial resolution. As a reference for the more detailed space utilization activities of space utilization arranged in the Regional Spatial Plans, Detailed Spatial Plans was created with the 1: 5000 scale map which has been governed by the Geospatial Information Agency. In the process of orthorectifying satellite imagery for this 1: 5000 scale map, ground control or Ground Control Point (GCP) is used for geometric correction and Digital Elevation Model (DEM) data. In this research, the optimal number of GCP usage for orthorectification process in Rational Function method is $21 \mathrm{GCP}$ using 2nd order polynomial
\end{abstract}

Keywords : Orthorectification, Satellite Imagery, GCP, Rational Function, Polynomial.

\section{INTRODUCTION}

As a reference for more detailed space utilization activities of spatial activities regulated in the Spatial Plan, a Detailed Spatial Plan with a 1: 5.000 scale map has been prepared by the Geospatial Information Agency (BIG). Used on a scale of 1: 5,000 , because on a scale map greater than or equal to 1: 5000, in addition to blocks, will also be drawn other elements such as channels and fences.

Pleiades is a satellite of high resolution satellite image producer made by Airbus Defense \& Space company. The Pleiades satellite produces satellite imagery data in two modes, namely the panchromatic mode and the multispectral mode. Satellite images in the panchromatic mode have a spatial resolution of 0.5 meters with a band number of 1 band (panchromatic), while satellite images in multispectral mode have a spatial resolution of 2 meters with a band number of 4 bands (VNIR Visible Near Infra Red). This satellite image has good specifications, so it is often used in survey planning and making thematic maps [4]. This satellite image is great for 1: 5.000 scale map with the required horizontal precision of $0.5-2.5 \mathrm{~m}$ [1].

In the process of orthorectifying this satellite image, a ground control point or Ground Control Point (GCP) is used for geometric correction of $\mathrm{x}$ and $\mathrm{y}$ positions. This GCP has an important role to correct data and improve the overall image. The accuracy of ground control points depends on the type of GPS used and the number of point samples on the location and the time taken. For 1: 5,000 scale mapmaking, a static geodetic GPS receiver of static method with 30-45 minute observation [1] was used. For the addition of z position information, Digital Elevation Model (DEM) data was added. DEM was a digital data describing the geometry of the earth's surface shape or parts thereof which comprises the set of coordinate points of the sampling result from the surface of the earth with the algorithm defining the surface using the coordinate set. For 1: 5.000 scale mapmaking, DEM can be used with 5-10 meter vertical accuracy [1].

*Corresponding author: tgh_hary@yahoo.com 
This study aims to examine the effect of the number of GCP with the uniform distribution pattern used in the image orthorectification process to the accuracy of the object analyzed by looking at the change of Independent Check Point position (ICP). It will also find out what the minimum GCP or limit on the process of orthorectification that entered the tolerance according to satellite image resolution and also will be sought GCP limitations so that the addition of GCP in the process of orthorectification does not affect the scale of the resulting image with respect to Root Mean Square Error (RMSE) which generated.

\section{DATA AND STUDY AREAS}

The location of this research was conducted in Lumajang Regency, East Java. The city coordinates are located at $112^{\circ} 53^{\prime}-113^{\circ} 23^{\prime}$ East Longitude and $7^{\circ} 54$ '- $8^{\circ} 23^{\prime}$ South Latitude. The research location in Lumajang City is one of the reasons for the orthorectification and not the usual rectification. Due to the relief form that varies from a height of 02000 meters.

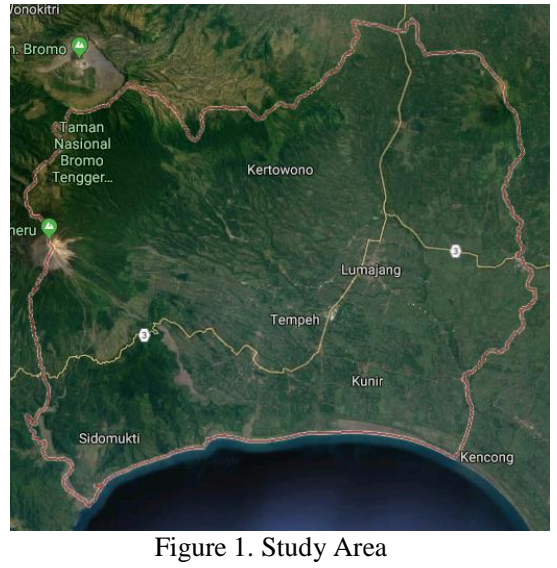

The data used in this research, among others :

a. Satellite images of Pleiades 1-A scene 033 with $0.5 \mathrm{x}$ meter panchromatic accuracy and 2 meter multispectral keteitian in East Lumajang District.

b. DEM SRTM / X-SAR data from TerraSAR-X satellite with a relative accuracy of $6 \mathrm{~m}$ and an absolute 16 meters lumajang district

c. Coordinate data of ground point amount 74 point measured by static methods for 30-45 minutes.

\section{METHODS}

In general, this research is conducted in five stages of research, namely the preparation stage consisting of problem identification process, literature study and data collection process, data processing stage, analysis phase and final stage in the form of report preparation.

Here is an explanation of the data processing stage: First about data collection. The data required in this research is, satellite image data of Pleiades 1-A of East Lumajang Regency, TerraSAR-X DEM data, and GCP and ICP coordinate data obtained from field measurement.

Second, choose which GCP and ICP to use. In accordance to the desired distribution and RMSE values of GCP and ICP measurements.

Third, the design of the control point is divided into 22 different models based on the number of GCP and ICP entered. In this study, the authors used 74 coordinate measurement data.

Fourth, Ortortification is the process of geometric correction of satellite imagery or aerial photographs to correct the geometric error of an image derived from the influence of topography, sensor geometry and other errors. The method used in this research is Polinomial Rational Function. Rational function is a simple mathematical model that reflects the correlation between pixels and poisisi on the ground. The use of this model is used when it does not have the information necessary for a rigorous mathematical model, such as because; sensors of different models, geometric imagery has been processed, data providers have done the calculation of mathematical model and distributed in the image, or do not have the overall image (the result of the cut).

Rational function has 3 order polynomial with order 1 requiring at least $7 \mathrm{GCP}$, order 2 requires minimum $21 \mathrm{GCP}$, order 3 requires minimum $41 \mathrm{GCP}$. The following polynomial orde $1[3,7]$ equation is

$$
\begin{aligned}
& \mathrm{x}=\frac{(1 X Y Z)(\mathrm{a} 0 \mathrm{a} 1 \mathrm{a} 2 \mathrm{a} 3)^{T}}{(1 X Y Z)(1 \mathrm{~b} 1 \mathrm{~b} 2 \mathrm{~b} 3)^{T}} \\
& \mathrm{y}=\frac{(1 X Y Z)(\mathrm{c} 0 \mathrm{c} 1 \mathrm{c} 2 \mathrm{c} 3)^{T}}{(1 X Y Z)(1 \mathrm{~d} 1 \mathrm{~d} 2 \mathrm{~d} 3)^{T}}
\end{aligned}
$$

where there are 7 parameters, including 4 in the numerator, and 3 and 1 constants in the denominator. In order to solve the Rational Function coefficient in this order of 3 , then there are at least 7 control points (GCP) required. The following polynomial orde 2 [3, 7] equation is

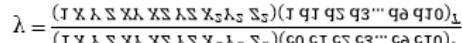

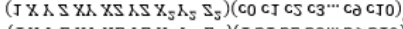

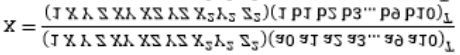

where there are 19 parameters, including 10 in the numerator, and 9 and 1 constants in the denominator. In order to solve the Rational Function coefficients in this 2 nd order, then there are at least 19 control points (GCP) required. The following polynomial orde $3[3,7]$ equation is

$$
\begin{aligned}
& \mathrm{x}=\frac{\left(1 X Y Z \ldots Y Z^{2} Z^{3}\right)(\mathrm{a} 0 \mathrm{a} 1 \mathrm{a} 2 \mathrm{a} 3 \ldots \mathrm{a} 18 \mathrm{a} 19)^{T}}{\left(1 X Y Z \ldots Y Z^{2} Z^{3}\right)(1 \mathrm{~b} 1 \mathrm{~b} 2 \mathrm{~b} 3 \ldots \mathrm{b} 18 \mathrm{~b} 19)^{T}} \\
& \mathrm{y}=\frac{\left(1 X Y Z \ldots Y Z^{2} Z^{3}\right)(\mathrm{c} 0 \mathrm{c} 1 \mathrm{c} 2 \mathrm{c} 3 \ldots \mathrm{c} 18 \mathrm{c} 19)^{T}}{\left(1 X Y Z \ldots Y Z^{2} Z^{3}\right)(1 \mathrm{~d} 1 \mathrm{~d} 2 \mathrm{~d} 3 \ldots \mathrm{d} 18 \mathrm{~d} 19)^{T}}
\end{aligned}
$$

in which there are 39 parameters, including 20 in numerators, and 19 and 1 constants in the denominator. In order to solve the Rational Function coefficient in this order of 3 , then there are at least 39 control points (GCP) required.

Fifth, The image has been orthorectificated if the Root Mean Square Error (RMSE) value less than equal to 0.25 meters. When that value has not been 
reached, it returns to the octhorectification process using the next GCP model (GCP used increases).

Sixth, When the Mean Square Error (RMSE) GCP value meets the $\leq 2.5$ meter requirement, the image has been orthorectificated. Then tested the geometric accuracy of the image with ICP coordinates. When the Mean Square Error (RMSE) ICP value does not meet $\leq 2.5$ meters (map scale 1: 5000), then return to octhorectification process using the next GCP model (GCP used increases).

Seventh, When the Mean Square Error (RMSE) ICP value meets the $\leq 2.5$ meter requirement, the image has been orthorectificated and can be used in scale of 1: 5000

Eight, If there is an unused image model (due to the use of the previous model), an orthorectification process remains to be performed. This step used to increase the number of GCP analyzes used with the maximum scale of maps that can be generated.

Then, Analysis of the effect of the number of GCPs with RMSE values done by looking at the RMSE GCP and ICP values displayed in image processing software. This value is related to how large the map scale can be made from the orthorectification image of the various given GCP variations. Planymetric precision analysis is divided into 3 parts order 1,2 , and 3 and each order is divided into classes 1,2, and 3. Classification of GCP numbers with geometrically generated image scales divided to 3 classes 1,2 , and 3.

Analysis of image distance accuracy done by calculating the distance between GCP from the outermost side and comparing the results with the distance measurement results in the image. The resulting distance difference can be used to determine the RMSE value. T-Test Statistics test is used to find the distance error value allowed for the 1: 5000 scale map. In this research, 3 sample of the best orthorectification image distance from each polynomial order is used. Image analysis of orthorectified results is performed on 1 image with the best accuracy. Includes pixel analysis, analysis of aquatic objects, transformation analysis, and analysis of high objects. From the analysis, it can be determined how many points of GCP at what order orthorectification needed for optimization of 1: 5 scale scale map.

\section{RESULTS AND DISCUSSION \\ IV.1. RMSE Results Orthorectification}

The Placement of GCP Point were located to represent terrain condition in order to increase the accuracy of RMSe. The process of orthorectification using the Rational Function method has 3 choices of polynomial order. $1^{\text {st }}$ order (Nearest Neighbors) requires at least $7 \mathrm{GCP}, 2^{\text {nd }}$ Order (Bilinear Interpolation) requires a minimum of $19 \mathrm{GCP}$, and $3^{\text {rd }}$ order (Cubic Convolution) requires a minimum of 39 GCP. Here is the distribution of 74 point measurement field.

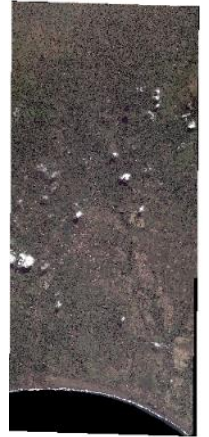

a)

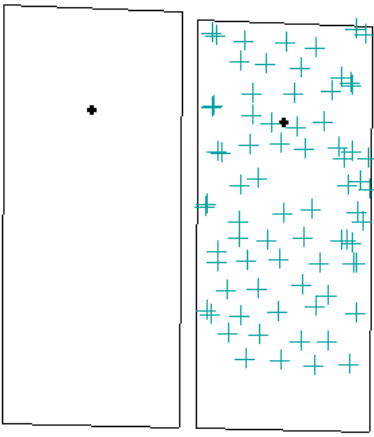

b) c)
Figure 1 a). High Resolution Image b). Image Area c). Output Measurement Point

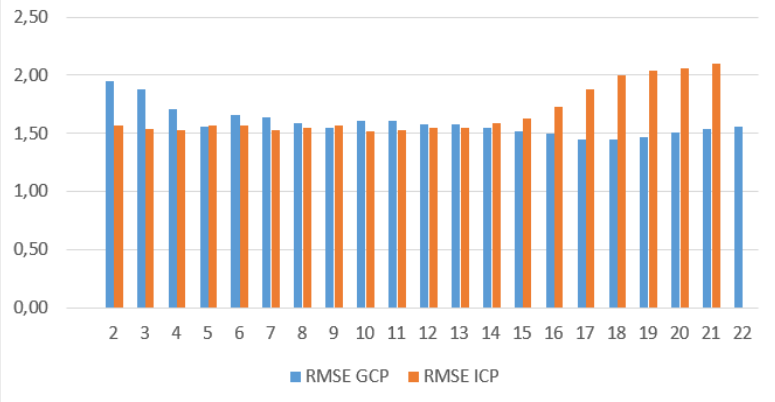

Figure 2. Graph of RMS Error GCP and ICP value of Orde 1 (in meters)

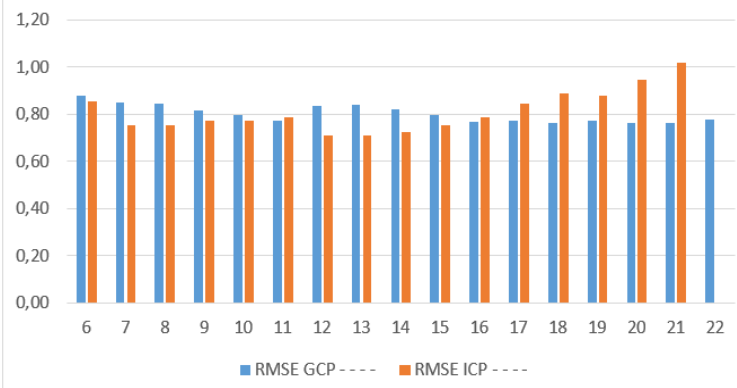

Figure 3. Graph of RMS Error GCP and ICP value of Orde 2 (in meters)

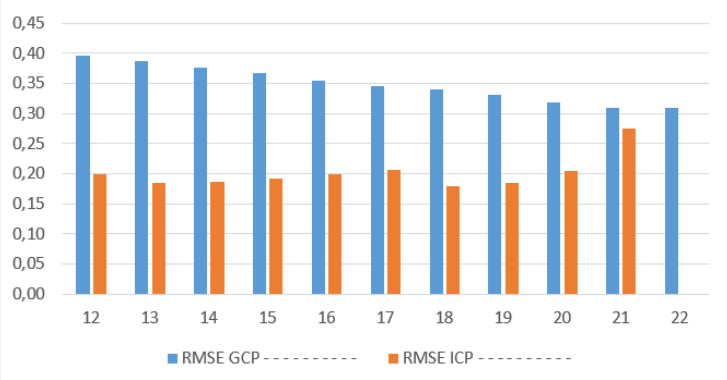

Figure 4. Graph of RMS Error GCP and ICP value of Orde 3 (in meters)

\section{IV.2. Analysis of Distance Accuracy and Test of T- Test Statistics}

In this approach, the distance analysis will only be performed on the best model of each order, ie at $1^{\text {st }}$ order with the use of $9 \mathrm{GCP}, 2^{\text {nd }}$ Order with the use of $21 \mathrm{GCP}, 3^{\text {rd }}$ order with the use of $41 \mathrm{GCP}$. 


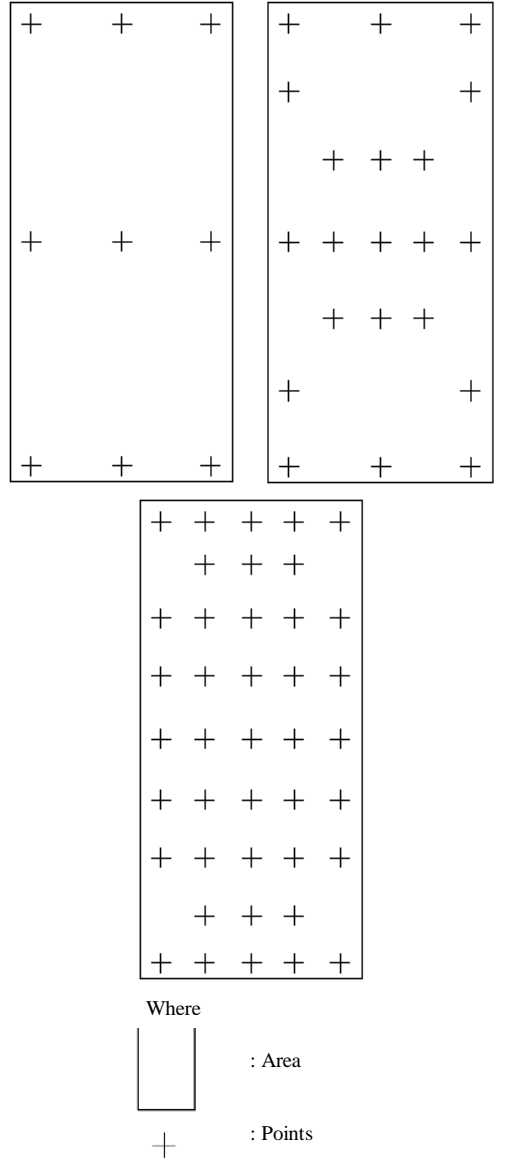

Figure 5. Point Distribution Point 9 GCP, 21 GCP, $41 \mathrm{GCP}$

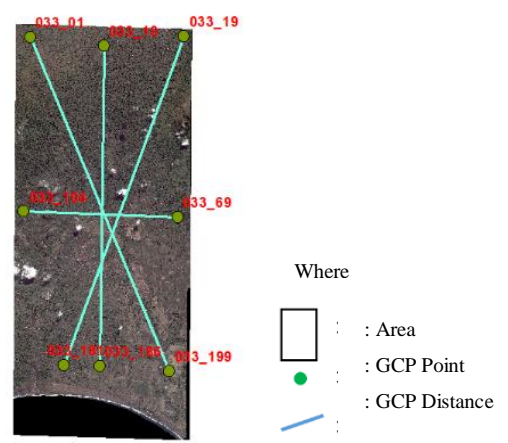

Figure 6. Sample Distance on distance accuracy test

If used $\alpha=5 \%$ and degrees of freedom $2(n=3)$, then obtained:

$\mathrm{t} \gamma, 1 / 2 \alpha=\mathrm{t} 1,0.05=4,303$ (from the student t-test table). With two-sided test method is calculated:

$\mathrm{X} 1=\mu-((\mathrm{t} 1,0.05 * \sigma \mathrm{x}) / \sqrt{2})=\mu-((4,303 * 0.25) /$

$\sqrt{2})=\mu-0.761$

$\mathrm{X} 2=\mu+((\mathrm{t} 1,0.05 * \sigma \mathrm{x}) / \sqrt{ } 2)=\mu+((4,303 * 0.25)$

$/ \sqrt{ } 2)=\mu+0.761$

If we use $\alpha=10 \%$ and degrees of freedom $2(n=3)$, then we get:

$\mathrm{t} \gamma, 1 / 2 \alpha=\mathrm{t} 2,0.05=2,290$ (from the student t-test table). With two-sided test method is calculated:

$\mathrm{X} 1=\mu-((\mathrm{t} 1,0.05 * \sigma \mathrm{x}) / \sqrt{ } 2)=\mu-((2,290 * 0.25) /$ $\sqrt{ } 2)=\mu-0,516$
$\mathrm{X} 2=\mu+((\mathrm{t} 1,0.05 * \sigma \mathrm{x}) / \sqrt{ } 2)=\mu+((2,290 * 0.25)$

$/ \sqrt{ } 2)=\mu+0,516$

Here is a sample test of distance from west of image (point 033_104) to east position of image (point $\left.033 \_69\right)$ at $\alpha=5 \%$ and $\alpha=10 \%$

Table 9 Test Results of t-test on Sample Distance west (point 033_104) to east (point 033_69) at $\alpha=$ $5 \%$

\begin{tabular}{|c|c|c|c|c|}
\hline Order & $\mathrm{x}$ & $\mathrm{X}_{1}$ & $\mathrm{X} 2$ & Result \\
\hline $1^{\text {st }}$ & 18963.818 & 18962.217 & 18963.738 & Accepted \\
\hline $2^{\text {nd }}$ & 18963.329 & 18962.217 & 18963.738 & Rejected \\
\hline $3^{\text {rd }}$ & 18962.874 & 18962.217 & 18963.738 & Rejected \\
\hline
\end{tabular}

Table 10 Results of t-test on Western Distance Samples (point 033_104) to East (point 033_69) at $\alpha=10 \%$

\begin{tabular}{|c|c|c|c|c|}
\hline Order & $\mathrm{X}$ & $\mathrm{X} 1$ & $\mathrm{X} 2$ & Result \\
\hline $1^{\text {st }}$ & 18963.818 & 18962.461 & 18963.493 & Rejected \\
\hline $2^{\text {nd }}$ & 18963.329 & 18962.461 & 18963.493 & Accepted \\
\hline $3^{\text {rd }}$ & 18962.874 & 18962.461 & 18963.493 & Accepted \\
\hline
\end{tabular}

From the calculations of $1^{\text {st }}$ order, $2^{\text {nd }}$ order, and $3^{\text {rd }}$ order with $\alpha=5 \%$, there is 1 result that is beyond the measure which means Ho is rejected (Ha accepted) on the test of the west-to-east distance sample in $1^{\text {st }}$ order. From the calculations of $1^{\text {st }}$ order, $2^{\text {nd }}$ order, and $3^{\text {rd }}$ order with $\alpha=10 \%$, there is 1 result which is beyond measure which means $\mathrm{Ho}$ is rejected (Ha accepted) on testing of west to east sample in $1^{\text {st }}$ order.

It can be concluded that although the best model for 1: 5000 scale map is available on $3^{\text {rd }}$ order with 41 GCP usage, but for optimal quantity GCP use $2^{\text {nd }}$ order with $21 \mathrm{GCP}$.

\section{IV.3. Pixel Image Analysis Result Ortortification}

In pixel image analysis ortorektifkasi results done on $2^{\text {nd }}$ order with the use of GCP as much as 21 point order 2, which in the previous explanation found that the $2^{\text {nd }}$ order with polynomial order 2 is the optimal model in the scale map 1: 5000. The following changes pixel size after the orthorectification process obtained from 5 sample point.

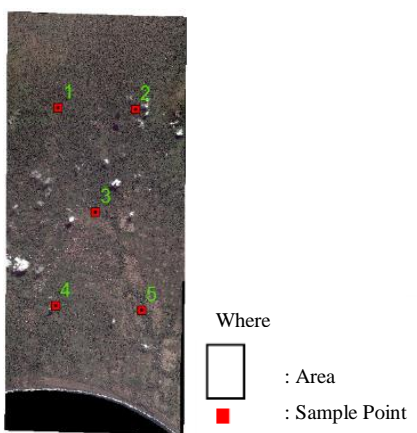

Figure 7. Sample Points Distribution 

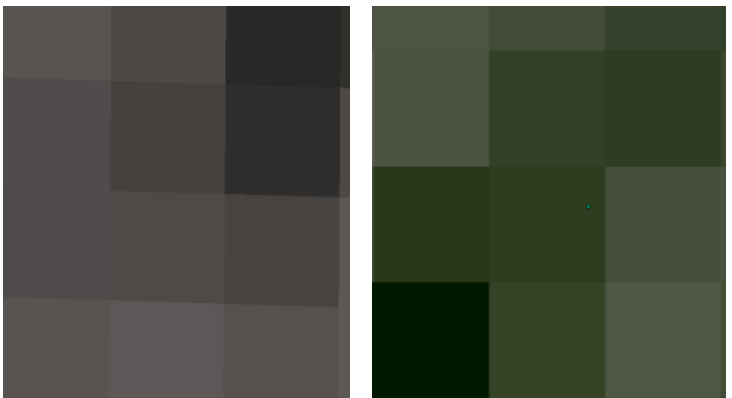

Figure 8 Differences of the Pixel Before and After Pixel Form

\section{CONCLUSION}

The conclusion from this research are :

a. In orthorectification process, so that RMSE GCP value $\leq 2.5 \mathrm{~m}$ can be used amount of GCP as much as $8 \mathrm{GCP}$ with polynomial of orde

b. In the process of orthorectification the addition of excessive amount of GCP does not alter the scale of the resulting map significantly. For order 1 orthorectification process, optimal GCP used is 9 GCP, 2nd order is $21 \mathrm{GCP}$, and order 3 is $41 \mathrm{GCP}$

c. Relation It is found that the order of polynomials used with the resulting image scale is in order 1 can be used for 1: 3000 1: 11000 scale map creation, order 2 can be used for 1: 1500 - 1: 5000 scale map creation, order 3 can be used to map scale $\leq$ 1: 1500 . The scale varies depending on the accuracy class of the map used

d. Although the best model in geometric accuracy is found in $3^{\text {rd }}$ order with the use of GCP as much as 41 points and using the order of polynomial 3. But for the scale map 1: 5000 , simply use model 7 with the use of 21 GCP with the order polynomial 2.

\section{References}

[1] Geospatial Information Agency. 2015. Mapping Aspect for Detailed Spatial Plans. Cibinong

[2] K. D. R. Ma, and R. X. Li. 2003. "Rational Functions and Potential for Rigorous Sensor Model Recovery". American : Department of Civil and Environmental Engineering and Geodetic Science, The Ohio State University, Columbus, OH 43210 (1i.282@osu.edu).

[3] Tao, C.V., and Y. Hu, 2001a. 3-D reconstruction algorithms based on the rational function model, Proceedings of ISPRS Joint Workshop "High Resolution Mapping from Space” 2001, 19-21 September Hanover, Germany, unpaginated CD-ROM

[4] Tempfli, K. 1991. DTM and differential modelling. In : Proceedings ISPRS and OEEPE joint workshop on updating digital data by photogrammetric method. Oxford, England
[5] Th. Toutin a, R. Chénier, Y. Carbonneau. 2002. "3D Models for High Resolution Images: Examples with Quickbird, Ikonos And Eros". Canada : Canada Centre for Remote Sensing.

[6] Turker, M. and A. O. Ok. Tanpa Tahun. "Comparison Of Different Mathematical Models On The Accuracy Of The Orthorectification Of Aster Imagery". Ankara, Turkey: Hacettepe University.

[7] Whiteside, A. 1997. Recommended Standard Image Geometry Models, OpenGIS Web Site, URL

http://www.opengis.org/ipt/9702tf/UniversalI mage/TaskForce.ppt 